\title{
Does Praising Intelligence Improve Achievements? An ESL Case
}

\author{
Rahima Akbar ${ }^{1} \&$ Nada Al-Gharabally ${ }^{1}$ \\ ${ }^{1}$ The Public Authority for Applied Education \& Training (PAAET), College of Basic Education (CBE), The English \\ Department, Ardiya, Kuwait \\ Correspondence: Rahima Akbar, The Public Authority for Applied Education \& Training (PAAET), College of \\ Basic Education (CBE), The English Department, Ardiya, Kuwait.
}

Received: March 28, 2020

Accepted: April 19, 2020

Online Published: April 24, 2020

doi:10.5430/ijhe.v9n3p279

URL: https://doi.org/10.5430/ijhe.v9n3p279

This research was funded by the Public Authority for Applied Education \& Training (BE-19-07).

\begin{abstract}
Praising is considered to have a positive effect on learners' motivations. Yet, what to praise and how to praise is an issue of controversy. The present study looks at the effect of praising ESL learners' writing efforts in English as opposed to evaluating their writing abilities in order to test Dweck (2007) theory of praising intelligence or effort. The investigation is based on a set of language parameters used in conventional evaluation of ESL writing pieces.

Forty adult English L2 learners at the women's College of Basic Education, English Department, who were enrolled in writing classes comprised the study's experimental and control groups. The study's findings indicate that praising the effort increases the learners' motivation and creates a relaxed teaching and learning environment.

The present study highlights the importance of incorporating the praise of a student's effort within the grading. Since grading plays a motivating factor on how well the learners' work progresses, it follows that it should strategically place importance on the teacher's feedback as well as clear instructions for improvement.
\end{abstract}

Keywords: praise, effort, intelligence, achievement, ESL learners, writing, grading, motivation

\section{Introduction}

\subsection{Setting the Scene}

Educators have always considered praising to have a positive effect on learners' motivations. Yet, what to praise and how to praise is an issue of controversy. A number of researchers have pressed the importance of praising the effort, not the intelligent, in order to maintain the students' positive motivations with the goal of maximizing students' confidence in their abilities and reaching out their highest potential. In her article 'The perils and promises of praise', Dweck (2007) explains that when educators praise intelligence, they are nurturing a very common belief amongst the students about intelligence as a 'fixed trait', whereby learners become excessively preoccupied by how smart they are, and as a result, avoid challenging tasks. The other side of the coin seems to be much more promising, when educators praise the students' effort, students in turn stop worrying about how smart they may appear and instead take on challenges until they achieve their goals. Thus a more positive perspective of how students' intelligence is seen is established.

As instructors of a number of consecutive writing courses for undergraduate students majoring in English, we have been continuously challenged by grading my students' essays, marking for hours to finish the papers of one class, yet not knowing whether we were helping any of them improve their writing skills. We noticed that students with poorer language and writing skills take up more grading time, which meant less time and feedback was allocated for more advanced students and hence less room for further growth. In fact, we were not even certain whether returning the students' graded papers including extensive feedback and recommendation for improvements actually helped our ' $\mathrm{C}$ ' students become 'B' students. Dragga (1985) describes the process of teachers' grading of their students writing pieces as a 'fault-finding' orientation, with the aim being finding enough things 'wrong' to justify lowering the students' grades. He also adds, students perceive such a grading process as a 'depreciation' rather than an 'appreciation' of their work. Even during teacher-student conference meetings to discuss students' works, things do not seem to get any better, since teachers would answer their students' queries about what they did wrong by bombarding the student with the errors the teacher found in their papers, and how to fix them. When we take into 
consideration the fact that there seems to be no empirical evidence that this type of teacher orientation to students' errors yields improved writers (Knoblauch \& Brannon, 1981), educators need to reconsider this conventional process of grading their students' written work in favor of a more supportive and effective method of grading. Dragga (1985) identifies such an alternative grading scheme as 'praiseworthy grading' of the students' elements of writing which the teacher finds as praiseworthy, such as effective organization of the ideas, explication of complicated ideas, or even simple mechanical accuracy. When teachers direct their students' attention to the positive aspects rather than the negative aspects of their writing, an improved attitude to writing can be instilled encouraging students to enjoy the task of writing and thus lowering their anxiety triggered inhibitions. The idea therefore appears to suggest focusing on the motivational level rather than the technical ability of writing.

In this research, we will investigate the effect of praising the effort students put into improving their writing as opposed to praising the mere outcome of writing. We will therefore look closely into the progressive pattern of students' written work after informing them that the evaluation of their work will depend on the extent to which they were following our feedback instructions on each drafted piece of writing. Accordingly, at the beginning of the semester, students will be clearly informed that an ' $A$ ' piece of writing might get a ' $C$ ' or even a ' $D$ ' if the student did not apply the feedback instructions provided on her first draft of writing. Likewise, a student whose level of writing is a ' $\mathrm{D}$ ' might be raised into a ' $\mathrm{B}$ ', or even an ' $\mathrm{A}$ ', if she successfully follows the teacher's guided instructions on her first draft. This progress pattern will then be cross-analyzed against previous writing classes for the same instructors, who followed a more conventional method of grading, namely: grading the outcome rather than the writing process.

Our aim is to find out if praising the effort would eventually motivate the students to write more coherent and lengthier essays than when their work was praised purely on the written outcome. We also would like to find out the effect of effort praising on the extent to which both weaker writers and more advanced writers demonstrate a progress in their initial level of writing.

In doing so, we will attempt to answer the following questions:

1. What is the effect of grading the students' efforts on their attitude towards a writing task?

2. What does the progress pattern of students who undergo this new technique of grading look like?

3. To what extent does the experimental grading technique of written work affect the weaker students?

4. To what extent does the experimental grading technique of written work affect competent writers?

\subsection{Significant Prior Research}

The key to students performing well in higher education is to ensure they are continuously engaged and highly motivated. Maclellan, (2005) argues that a social-cognitive perspective looks at motivation as dynamic, context-sensitive and changeable. This is why it is quite challenging for teachers to constantly work at developing new methods to keep students motivated. One of the sure ways teachers can motivate students is by praising them. Sadly, however, according to suggested research, this is implemented only half as much (if that) in both general and special education classrooms (Brophy, 1981; Hawkins \& Heflin, 2011; Kern \& Clemens, 2007; and Dweck, 2007).

Hawkins \& Heflin, (2011) point out that a praise statement has to show a behavioral description so that students may get some feedback, which guides their learning and enhances their performance. They claim that a praise statement, for example, such as 'Good job!' is inadequate because it is non-specific and lacks a behavioral description. However, such a statement becomes acceptable when expanded to include a behavioral element: "You located eight strong source documents for your essay. Good job!". Moreover, they believe that praise should concentrate on certain examples of student effort or achievement (e.g., "It's obvious from your grade that you worked hard to prepare for this quiz. Great work!"). This will help students see a direct link between their effort and their improved academic performance. As such, to them, this is considered positive feedback (Hattie and Timperley, 2001).

Focused on the distinction between private praise and public praise. The instructor should take into consideration the student's preference in receiving praise based on the context where it is utilized. Students vary in that some prefer private praise while others prefer public praise. Moreover, the kind of encouragement given by teachers to students and how the students cope with feedback has huge implications. In fact, when praise is used unwisely or improperly, it may gravely impact the students' execution of a given task; shifting them from an "I can do this even though it's hard" frame-of-mind to fearing the enormity of the task at hand and giving up before even trying (Hodgman, 2015). According to Gable et al. (2009), successful praise comes with both verbal and non-verbal cues. For example, when a student is praised without eye contact from the teacher, it may have a counterproductive effect. 
Hodgman (2015) investigated student praise in the modern classroom. His main concern was the use of praise notes as a productive motivational tool. He outlined research on the use of praise by instructors in the classroom and in the context of student motivation. Hodgman specifically discusses the use of praise-notes to productively induce student performance and engagement. His conclusions demonstrate that that praise can be an effective tool to motivate students if used appropriately. Specifically, teacher-written praise notes can be used to motivate younger students to employ behaviors that will increase student performance and create a more positive and engaging classroom atmosphere.

Haimovitz and Henderlong-Corpus (2011) examined the effects of person praise and process praise on college students' motivation. They asked 111 students to work on three puzzle tasks and accordingly they either received person praise, process praise, or no praise. Haimovitz and Henderlong-Corpus found out that process-oriented praise enhances intrinsic motivation and perceived competence more than person-oriented praise, and that these effects vary as students' progress toward the attainment of their degree. While person praise decreased motivation for sophomores and juniors, process praise increased motivation for seniors. In the case of freshmen students, there were no significant differences with their levels of motivation. This conclusion coincides with the conclusion arrived by Conroy et al. (2009), who found that process praise is more advantageous in increasing student performance than person praise. On the other hand, Skipper and Douglas (2012) seem to believe that process praise may not be inherently positive and person praise was shown to be particularly detrimental. Similarly, Kohn (1996) is of the idea that praise can have particularly detrimental outcomes for children. For example, praising a child can be seen as a manipulative act that could create praise junkies, decrease student interest in activities and attention, and steal pleasure by wanting to be the center of attention. On a similar issue, Kamins and Dweck (1999) state that person praise, even when positive, may lead to vulnerability in children.

In this vein, researchers propose appreciating what a child has accomplished by focusing on the effort put into the task, thus leading to better learning outcomes than by labeling a child as a whole. Toshalis and Nakkula (2012) have therefore proposed that effort matters most, as intelligence is not a fixed trait. Although individuals are born with biological aptitude that allows them to excel at particular fields than others, functional intelligence can actually be acquired. In other words, despite one's intelligence, academic achievement can change according to the level of effort a person puts into a task. And ordinarily, the learner's level of motivation determines how much effort s/he might be willing to put into a certain task. Students who are willing to believe that individuals are born with innate smartness are more likely to give up at their first academic obstacle, simply because they think they lack the intelligence to resolve the issue at hand.

On the other hand, students who believe that effort can make a difference are more likely to show stronger persistence. Toshalis and Nakkula (2012) therefore claim that when students are taught to associate their achievement with the amount of effort, which they can control, rather than innate ability, which they may or may not possess, their motivation to try will also grow. This means that praising a learner's intelligence is likely to do more harm than good. Dweck (2007) describes teachers who praise students' intelligence as fixed-mind set creators. They nurture minds which care first and foremost about how smart they will be judged, and as a result, shy away from opportunities where they might fall into errors, simply because they wish to avoid situations that could potentially reveal their 'dumbness'. Eventually, such an attitude creates students who are unwilling to make any effort. Teachers who praise effort, on the other hand, are growth mind-set creators, who encourage students to increase their efforts when faced with eminent failure. Cimpian et al. (2007) report similar findings across children and adolescents, pointing out that praising intelligence gives the learner temporary feelings of pride, followed by a series of negative effects, including cheating practices. Those who were praised for effort, however, dealt more positively with challenging tasks, and developed a growing mind-set that believes that working hard will develop their skills and make them intelligent. And finally, Haydon and Musti-Rao (2011) conducted a case study to examine the effect of praise on math instruction at a middle school. They found that behavior-specific praise had a positive impact on student participation, classroom atmosphere and teacher-student interactions. They claimed that praise is underused as an effective instructional strategy.

\subsubsection{Praise Notes}

The praise notes that instructors write to students may have a positive influence on their achievement. These notes are short written statements acknowledging desirable student efforts and behaviors. They are often used to motivate students and increase their appropriate social behavior as well as strengthen teacher-student relationships. Moreover, Caldarella et al. (2011) claimed that teacher-written praise notes significantly decreased tardiness in an elementary school setting. Similarly, Nelson et al. (2010) show that the use of teacher-written praise notes in a middle school 
significantly reduced the number of student discipline referrals at the school administration. For this reason, it is often useful to find out what sort of comments impact students positively and accordingly familiarize teachers on when and how to utilize them (Walker, 2009).

According to Wheatley et al. (2009) written praising comments can be given out whenever the student accomplishes the desired behavior for a set period of time usually determined by teachers. They add that it may be necessary to periodically reward teachers with items such as gift certificates or service vouchers. Finally, in order for praise notes to be successful, teachers need to monitor the effects of this practice on students. In line with the research presented above, teachers need to confirm that praise is given in a frequent, contingent, and specific manner to increase effectiveness. However, when noticing that students do not seem to demonstrate the desired behavior following receiving initial praise notes, teachers should not give much attention to these students in order to eliminate potentially attention-seeking behaviors (Caldarella et al. 2011). This is why teachers are encouraged to keep a journal that monitors praise notes practices both quantitatively and qualitatively. For example, for a certain period of time, teachers could record how many praise notes were distributed daily, to whom and for what purpose (Partin et al. 2009).

\subsubsection{The Strategic Use of Praise in an ESL Context}

In terms of acknowledging the skill of writing in an ESL context, teachers have rigorously thrived to design strategies that may help their students improve their composition skills. However, when faced with large-size classes, and varying proficiency levels, teachers adapt by providing their students with written feedback. In a study conducted by Razali and Jupri (2014), three types of written feedbacks were investigated in an English L2 classroom on students at university level, namely: suggestion (explicitly recommending remediation that establishes a clear action for improvement), criticism (expressions of dissatisfaction or negative comments) and praise (attributing credits for some characteristics or skills). The purpose of this investigation was to gauge which of the three praise types encouraged students to do better revision of their written work. The study revealed that criticism tends to push students to write lengthier pieces with better overall proficiency features, because it targets specific instruction. The study also revealed that all three types of feedback have actually led students to revise their written work and present them at a more improved level. Contrary to that, Hyland and Hyland (2001) claim that mitigated criticism seems to be a source of confusion, especially when it is not coupled with an explicit suggestion for an act of revision. The two researchers added that, teachers' feedback on their students written work is, 'a practice that carries potential dangers and requires careful consideration' (2001: 207). Further data by Ferris (1997) reveals that teachers' feedback, whether presented in the form of a suggestion or criticism, will potentially lead to better work quality by the students than positive comments that cannot be acted upon.

In a statistical study, Graham and Perin (2007), utilized a method called meta-analysis, which allows researchers to test the research consistency and strength. They point out eleven key elements for effective adolescent writing instruction. One of these elements was assigning students with specific, reachable goals for the writing task they are to complete. Our intention in this research is to employ such key elements when providing our sample of students with feedback on their initial draft of writing, in the hope that it will provide them with strategic guidance and achievable objectives that are sure to enhance their writing skills and enable them to strengthen their weaknesses via error self-analysis.

\subsection{Context of this Study}

In this research, we are planning to test Dweck's (2007) theory on the 'Perils \& Promises of Praise' in which she presents a formula on how to impart effort-based praise to learners in order to increase their motivation and yield perseverance. In addition, we intend to establish an innovative grading scheme whereby a learner's piece of writing will be evaluated against one's own work and skills rather than a set of prescribed skills that has to be adhered to for a potential grade. By doing so, we claim that evaluating the process of writing - by suggesting instructions on how to revise a piece of writing - is enormously more effective than evaluating the student's actual skill of writing (which can hardly develop across a 10-week time frame).

Since grades have often been the ultimate goal of adult learners, we therefore believe that we should use them as a motivating factor to ensure our sample's compliance with the issues under investigation. The way to achieve this is to inform students that they will be rewarded for the extent to which they can understand the feedback instructions and fulfill them in their final draft. By doing so, we are trying to provide our students with two aspects for learning; challenging oneself, which is less intimidating than challenging others or be challenged by others, and providing the learner with motivation to progress (in the hope of enhancing grades). Our intention is to allow the learner to become aware of a new process of evaluation and grading. More specifically we hope to enable students to understand that 
their writing efforts, which involve adhering to the teacher's instructions, are being appreciated rather than deprecated through better grades. The ultimate goal is to work on the malleability of functional intelligence by motivating students to work harder, persevere in overcoming obstacles, and never give up against setbacks.

\section{Methodology}

\subsection{Study's Sample}

At the women's College of Basic Education, English Department, students are required to finish two academic writing courses as prerequisites for a number of linguistic and literature future courses on the student major-sheet. Both courses are designed to prepare students - who upon graduating will become future English teachers - to write paragraphs and essays on various themes.

Implementing a purposeful sampling procedure, forty female adult English L2 learners, who were enrolled in two writing classes (as part of the preparatory basic teaching skill courses), taught by two professors (also the researchers of the present study) comprised the study's experimental and control groups ( $23 \& 17)$. The two groups were randomly assigned as the control vs. experimental groups, where each group initially started with 24 students. However, as a number of students dropped out, our samples shrank to 23 in the experimental group and 17 in the control group. Participants were all female freshmen students, presented with various English proficiency levels, who have recently joined the English department at the College of Basic Education in Kuwait.

\subsection{Research Design}

Each group was assigned to write two pieces of writing in two different themes: narrative and descriptive. For each assignment, the students were asked to write an initial draft, followed by an edited final draft. Each piece of writing was graded for content (a proper topic sentence, enough supporting sentences, a concluding sentence, as well as unity, coherence and cohesion) and form (grammar, spelling and format). The writers' first drafts were guided by a set of instructions to assist students in presenting an improved edited final draft. Only the second draft received a grade of $\mathrm{A}-\mathrm{F}$ based on how well the students followed their professors' written instructions in the experimental group, and how well they generally wrote in the control group.

Rather than the sole betting on the scores of the students to answer the questions of the present research, the researchers adopted a phenomenological approach, where the qualitative data should be elicited to validate or invalidate the obtained scores using a posteriori (empirical knowledge) of the participants (Parodi, 2008). Thus, by the end of the semester, the students' pieces of writing from the two groups were evaluated based on the same variables mentioned above (content and form) and compared to reveal how well the two groups benefited from the course instructions. Rubrics of the writing pieces of the two groups (control \& experimental) comprised the study's quantitative data, to reflect on the writing progress of the two groups, which were later analyzed quantitatively based on the average scores obtained by each group.

Subsequently, participants of the experimental group received predesigned flash cards and were prompted to reflect (in writing using the language they prefer) on how they felt about the new grading experience. The qualitative data were coded and analyzed to find out how the students perceived the new grading scheme (effort grading). Beyond everything, it is the emotional interactions of the learner which would ultimately have its count in the success rate of any teaching procedure.

Both quantitative and qualitative data were triangulated to justify the interpretations of the results.

\section{Results}

\subsection{Statistics and Data Analysis}

The current study investigated the students' performance in two groups: experimental and control. While the writings of the control group were corrected and returned to the students with simple comments, the experimental group's writing was evaluated in terms of two phases: praise comment and post praise comment. The students' written work was evaluated based on content and form in both groups, and the results of two groups were analyzed and compared between groups. The average percentages of grades of both content and form in the two groups are represented in Table 1. 
Table 1. Average scores of controls vs. experimental groups per each assignment

\begin{tabular}{lcc}
\hline Assignment Label & Control Group & Experimental Group \\
\hline 1/draft 1/content & $62.1 \%$ & $54.3 \%$ \\
1/draft 1/form & $61 \%$ & $53.3 \%$ \\
1/draft 2/content & $70.3 \%$ & $70.8 \%$ \\
1/draft 2/form & $71.1 \%$ & $72 \%$ \\
2/draft 1/content & $62.4 \%$ & $68.4 \%$ \\
2/draft 1/form & $62.1 \%$ & $68.2 \%$ \\
2/draft 2/content & $70.7 \%$ & $81.7 \%$ \\
2/draft 2/form & $71.8 \%$ & $81.9 \%$
\end{tabular}

As Table 1 shows, in the first assignment, the control group scored an average of $62.1 \%$ for content, while the experimental group scored an average of $54.3 \%$. In the second draft, the control group reached an average of $70.3 \%$, reflecting a $7.8 \%$ increase in the grades on content of their first assignment. The experimental group received praise written on their first draft, and in the second draft, the average grade for content increased by $17.1 \%$.

In order to verify the results, a second assignment was given to the students in both groups. The control group scored $62.4 \%$ in the second assignment for the evaluation of content, an increase from the first draft of $0.3 \%$, yet a drop of $7.9 \%$ from the second draft of the first assignment. The second assignment of the control group increased to reach an average grade of $70.7 \%$ for content. In the experimental group, however, the content of the second draft gained an average of $68.4 \%$, which reflects an increase of $14.1 \%$ in comparison to the first draft in the first assignment, and a mere $2.4 \%$ from the second draft of the first assignment. After including praise, the second draft of the second assignment scored an average $81.7 \%$ in terms of content. Figure 1 reflects the difference between the two groups in content grades.

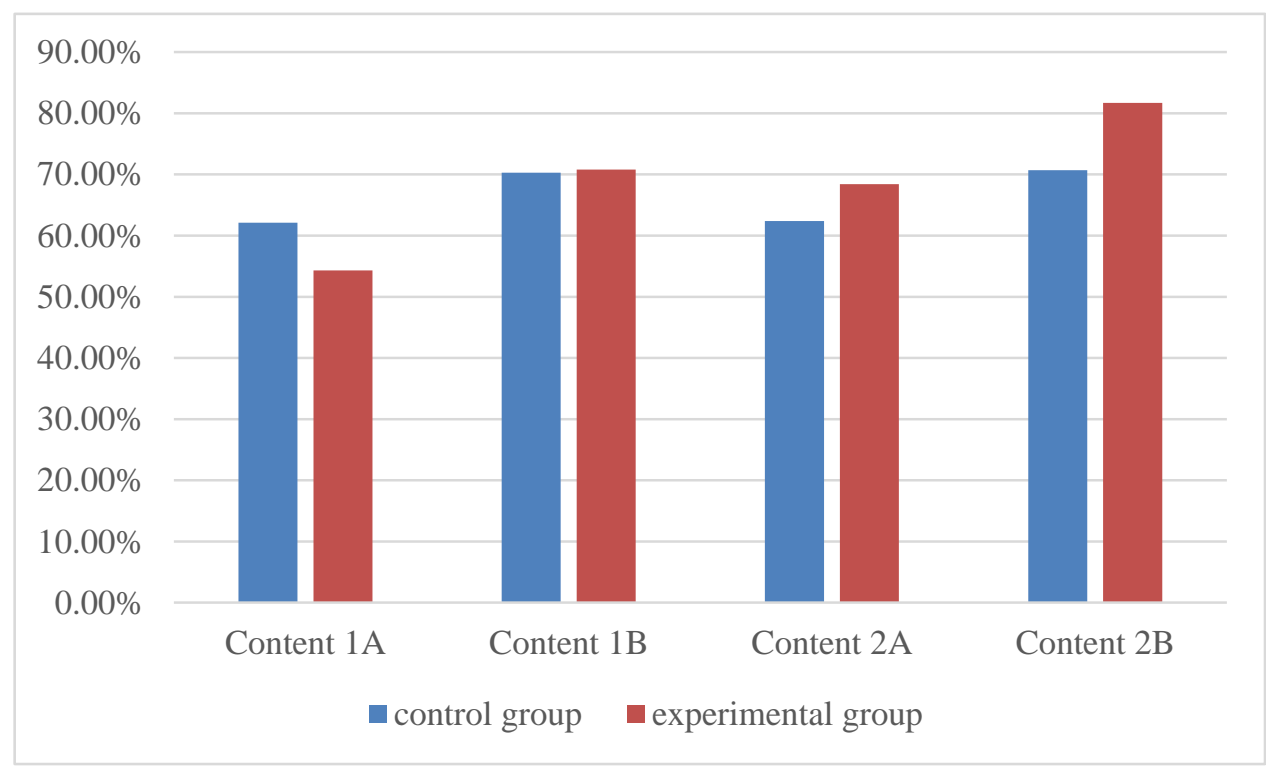

Figure 1. Average grades for content in both groups

The grading of form in both groups presented comparable results. In the first assignments, the control group scored an average $61 \%$ in the first draft, and $71.1 \%$ in the second draft, reflecting an increase of $10.1 \%$. Yet, in the second assignment, the grades fall back to $62.1 \%$ in the first draft $(9 \%$ difference from the second draft of the first assignment). The average percentage of form increases in the second draft of the second assignment to reach $71.8 \%$. This increase reflects a steady and stable advance in the grades of the control group, revealing great similarities in percentages of both assignments. The case differs in the experimental group. The average percentage for form in the first draft of the first assignment in the experimental group was 53.3\%, and in the second draft an increase of $18.7 \%$ occurred. In the second assignment, the students scored an average of $68.2 \%$, only $3.8 \%$ decrease from the grades of 
the second draft of the first assignment, and an increase of $15.1 \%$ from the first draft of the first assignment. In the second draft, the average rose to $81.7 \%$ (an increase of $13.3 \%$ from the first draft of the same assignment). Figure 2 displays the grades for form in both groups.

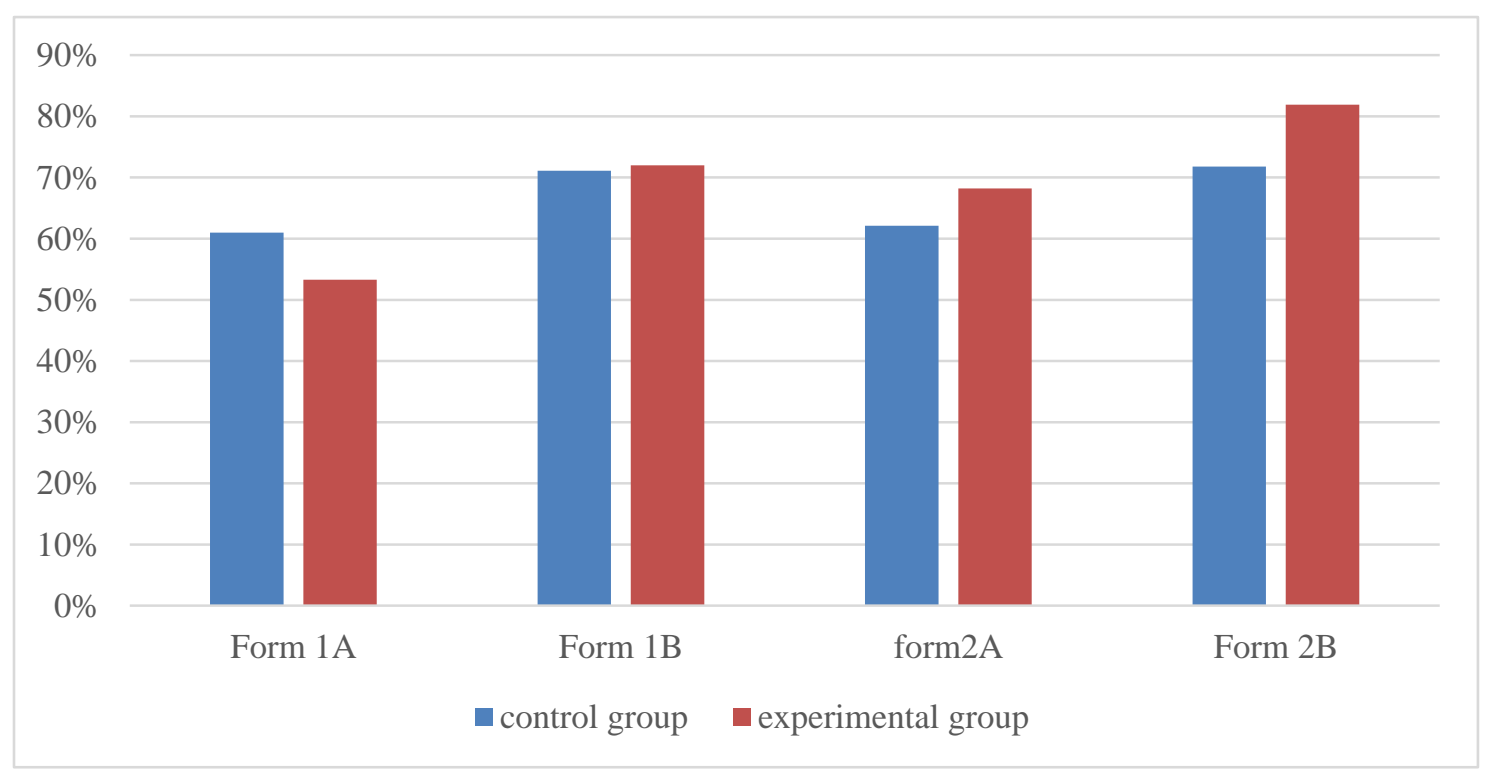

Figure 2. Average grades for form in both groups

In order to understand the diverse effect of praise on individual abilities, it was necessary to analyze the grades obtained by both weak and advanced students in terms of both content and form, and measure the difference of the percentages obtained in each draft. Figure 3 reflects the grades for content in the case of the weakest students in both groups. In the control group, the weakest student received $20 \%$ on content in the first draft and $10 \%$ on form. For her second draft, the student gained the same percentage in content, yet the grade of form increased to $30 \%$. The percentage obtained for content of the second assignment remained $20 \%$ in both drafts. In form however, the percentage in the first draft of the second assignment retreated to $10 \%$ and increased to only $20 \%$. The weakest student in the experimental group, on the other hand, started with only $6.7 \%$ percentage for content, and $20 \%$ for form in the first draft of the first assignment. In her second draft, the percentage obtained for content increased to $40 \%$, while in the case of form the student's percentage reached a staggering $73.3 \%$. The second assignment advanced in terms of content, as the student scored $20 \%$ in the first draft and $6.7 \%$ in the second draft, yet for form, she received $26.7 \%$ in the first draft and the percentage remained the same in the second draft.

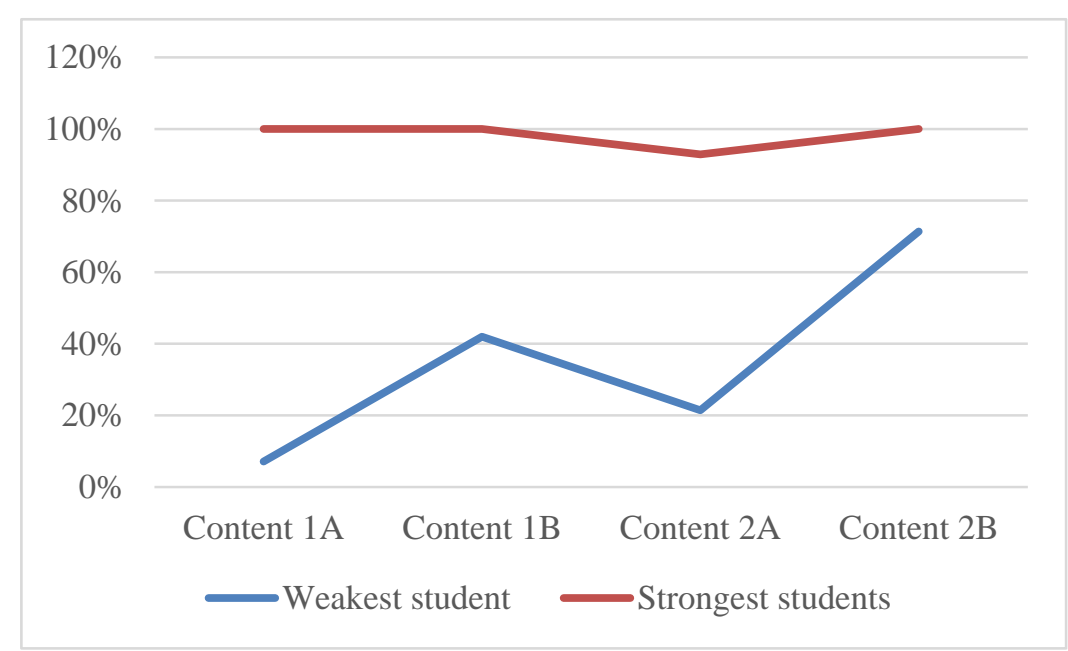

Figure 3. Percentages of the weakest students' assignments for content 
As for the strongest students, the increase of grades was less, considering the fact that they have almost obtained a full grade. In the control group, the highest grade in the first draft of the first assignment was $86.6 \%$ for content and $80 \%$ for form. In her second draft, the same students received $93.3 \%$ for content and $90 \%$ for form. The grades in her second assignment seemed very similar. The student received $86.6 \%$ for content and $90 \%$ for form in the first draft of the second assignment, and $93.3 \%$ for content and $90 \%$ for form in her second draft. As for the highest grade in the first draft of the first assignment in the experimental group, the best percentage was $93.3 \%$ for content and $80 \%$ for form. In the second draft, the same student received $90 \%$ for both content and form. In her second assignment, the student received $86.6 \%$ for content and $80 \%$ for form in the first draft. After praise however, her grades in the second draft increased to $90 \%$ for content and $100 \%$ for form. Figure 4 below reflects the steady yet evident increase of grades represented by the best student in class.

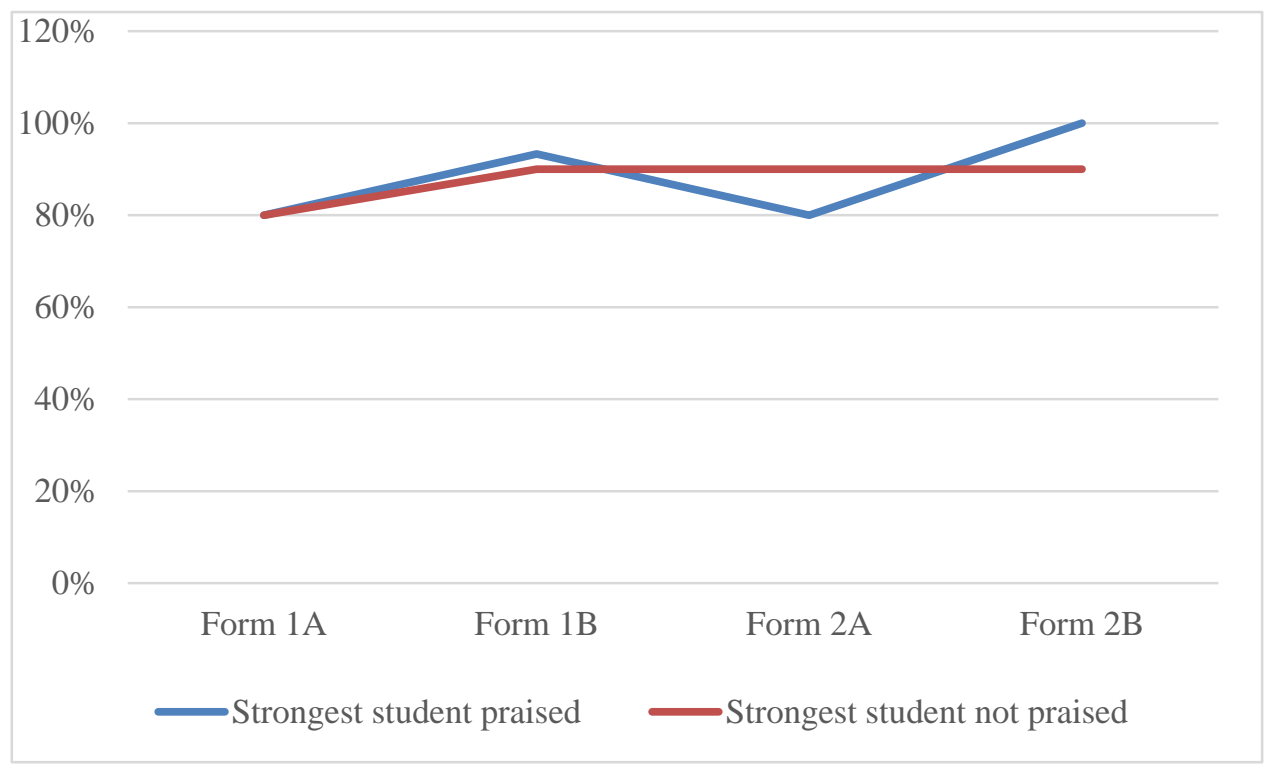

Figure 4. The percentages of the advanced student's two assignments for form

\section{Discussion \& Findings}

\subsection{Assignment Scores}

The first assignment scores of students from the two groups: the control and the experimental, generally indicate a clear discrepancy in the students' skill of writing. An average score on the first assignment of $62 \%$ and $61 \%$ for content and form respectively, compared to an initial score of 54\% and 53\%, reflects a possible outperformance of the control group in their initial levels of writing in English. Although the control group gained the lead towards a higher score in the revised draft of their initial work (60-70\%), the experimental group seems to have made a higher jump at their level (54-70\%). The Figures indicate the higher efficiency of the 'Praising of Intelligence' measure when compared to the conventional grading system in ESL writing.

The second assignment scores reflect a setback of the control group on both content and form when carrying out a new assignment. When compared to the experimental group, their scores show an insignificant setback in the scores between the initial scores of assignments 1 and 2 . This is a very important indication that reflects how the students from the experimental group have been more capable of using the required knowledge even when they are exposed to a new theme of writing. The control group, on the other hand, has not been capable of doing so.

In assignment 2, once again, the two groups show distinctive variability with the experimental group exhibiting precedence in their first draft. Both groups show a marked progress in terms of form and content. Yet, the experimental group shows a higher leap from $68 \%$ into $81 \%$ compared to the control group's progress, which reveal only a slight boost of 8-9\% for form and content. It would therefore be safe to state that a much more advanced and stable progress pattern has been presented by ESL students who have been exposed to effort-type praising over intelligence-type praising.

The investigation of the weakest versus advanced student of the two groups indicates that weak students' scores per content show a persistent level of no progression by the control group across all assignments. On the contrary, the weak students' content scores show a steady advancement during both first and second assignments. As for the 
strong students in the two groups, once again, our findings show a comparatively higher progression in the experimental group. However, due to almost obtaining the full grade on form, there seems to be no more room for progression in comparison to the scores of the weak students. Accordingly, the study's findings assert that praising effort over intelligence is key in presenting a constructive evaluation system to ESL learners.

\subsection{Perceptions on 'Praise Effort'}

Investigation of the 'effort' grading scheme on participants' flashcards presented the following views (See Table 2)

Table 2. Participants' views on 'effort' grading scheme

Difficulties in comprehending the professor's instructions

$12 \%$

Unfamiliarity of the new evaluation system

$15 \%$

Positive final outcomes by the end of the semester made it worthy

$30 \%$

'Praise effort' requires more work on the side of the students to gain a good grade

$22 \%$

'Praise effort' requires more practice to reach the ultimate efficacy

$9 \%$

We would like to try it in other courses

$42 \%$

As presented in Table 2, such views indicate three aspects of the 'Praise effort' grading scheme:

a. All students' negative views of the scheme are related to their unfamiliarity of the system. The application of 'Praise effort' in further courses would certainly make the experience more pleasant.

b. Despite the students' complaints about the extensive effort they have to put in, the progress made the 'Praise effort' scheme appear worthy.

c. All in all, the students tend to admire 'Praise effort' scheme, they believe it merits being applied in future courses.

\section{Conclusion and Future Recommendations}

The present study looks at the effect of praising ESL learners' writing efforts in English as opposed to evaluating their writing abilities. The investigation is based on a set of language parameters used in conventional evaluation of ESL writing pieces.

The study's findings suggest a very promising progression profile for ESL learners in general and for weak ESL learners in particular. The study also calls upon educators to praise the students' efforts rather than their ability in writing tasks during the process of teaching and learning. Our findings indicate that praising the effort has helped to maintain or even increase the learners' motivation, which in turn is known to create a relaxed teaching and learning environment. As Hyland and Hyland (2001) propose, mitigated criticism of the student's work could be a source of confusion if not coupled with explicit strategic revision measures of their work. Teachers should therefore be quite cautious when providing students with feedback on accomplished work. The study's findings also appear to be in line with Haimovitz \& Henderlong-Corpus (2011) findings, suggesting that process praise enhances the learner's intrinsic motivation and perceived competence. When the students were given a new theme of writing, their first draft seems to have partially maintained the progress they made during the writing of the previous assignment. Implementing the conventional way of praising, on the other hand, seems to have lost its effect when the students moved to the second piece of writing.

The present study proposes to highlight the importance of incorporating the praise of a student's effort within the grading. Since grading plays a motivating factor on how well the learners' work progresses, it follows that it should strategically place importance on the teacher's feedback as well as clear instructions for improvement. Despite the few criticisms of the praise effort strategy, it seems that once the students become more familiar with the system, they develop much more positive attitudes towards this technique. We therefore suggest introducing the technique at an earlier stage to students during their high school years. It is also worth mentioning at this stage that the study has been conducted on a limited sample of ESL learners. We therefore recommend the replication of this study on ESL learners in various other contexts to validate the findings of the present study.

\section{Acknowledgements}

The researchers would like to thank the Public Authority for Applied Education and Training (PAAET) for funding this research (Be-19-07). Also, the researchers would like to express their gratitude to Professor Hanan A. Taqi, for spending her valuable time and effort in the supervision and proof reading of this manuscript. 


\section{References}

Brophy, J. (1981). Teacher praise: A functional analysis. Review of Educational Research, 51, 5-32. https://doi.org/10.3102/00346543051001005

Burnett, P. C. (2001). Elementary students' preferences for teacher praise. Journal of Classroom Interaction, 36(1), 16-23.

Caldarella, P., Christensen, L., Young, K. R., \& Densley, C. (2011). Decreasing tardiness in elementary school students using teacher-written praise notes. Intervention in School \& Clinic, 47(2), 104-112. https://doi.org/10.1177/1053451211414186

Cimpian, A., Arce, H., Markman, E. M., \& Dweck, C. S. (2007). Subtle linguistic cues impact children's motivation. Psychological Science, 18, 314-316. https://doi.org/10.1111/j.1467-9280.2007.01896.x

Conroy, M. A., Sutherland, K. S., Snyder, A., Al-Hendawi, M., \& Vo, A. (2009). Creating a positive classroom atmosphere: Teachers' use of effective praise and feedback. Beyond Behavior, 18(2), 18-26.

Dragga, S. (1985). Praisworthy Grading. Journal of Teaching Writing, 4(2), 264-268.

Dweck, C. S. (2007). The perils and promises of praise. Early Intervention at Every Age, 65(2), 34-39.

Dweck, C. S. (2006). Mindset: The new psychology of success. New York: Random House.

Ferris, D. R. (1997). The influence of teacher commentary on student revision. Tesol Quarterly, 31(2), 315-339. https://doi.org/10.2307/3588049

Gable, R. A., Hester, P. H., Rock, M. L., \& Hughes, K. G. (2009). Back to basics: Rules, praise, ignoring, and reprimands revisited. Intervention in School and Clinic, 44(4), 195-205. https://doi.org/10.1177/1053451208328831

Graham, S., \& Perin, D. (2007). Writing Next: Effective strategies to improve writing of adolescents in middle and high schools - A report to Carnegie Corporation of New York. Washington, DC: Alliance for Excellent Education. www.carnegie.org/literacy.

Haimovitz, K., \& Henderlong-Corpus, J. (2011). Effects of person versus process praise onstudent motivation: Stability and change in emerging adulthood. Educational Psychology, 31(5), 595-609. https://doi.org/10.1080/01443410.2011.585950

Halvorson, H. (2014). The Key to Great Feedback? Praise the Process, Not the person. https://99u.adobe.com.

Hattie, J., \& Timperley, H. (2007). The Power of Feedback. Review of Educational Research, 77(1), 81-112. https://doi.org/10.3102/003465430298487

Hawkins, S. M., \& Heflin, L. J. (2011). Increasing secondary teachers' behavior-specific praise using a video self-modeling and visual performance feedback intervention. Journal of Positive Behavior Interventions, 13(2), 97-108. https://doi.org/10.1177/1098300709358110

Haydon, T., \& Musti-Rao, S. (2011). Effective use of behavior-specific praise: A middle school case study. Beyond Behavior, 20(2), 31-39.

Hyland, F., \& Hyland, K. (2001). Sugaring the pill. Praise and criticism in written feedback. Journal of Second Language Writing, 10(2001), 185-212. https://doi.org/10.1016/S1060-3743(01)00038-8

Hodgman, M. R. (2015). Student Praise in the Modern Classroom: The Use of Praise Notes as a Productive Motivational Tool. Journal of Education and Training 2015, 2(1), 41-48. https://doi.org/10.5296/jet.v2i1.6142

Kamins, M., \& Dweck, C. S. (1999). Person vs. process praise and criticism: Implications for contingent self-worth and coping. Developmental Psychology, 35(3), 835-847. https://doi.org/10.1037/0012-1649.35.3.835

Kern, L., \& Clemens, N. H. (2007). Antecedent strategies to promote appropriate classroom behavior. Psychology in the Schools, 44(1), 65-75. https://doi.org/10.1002/pits.20206

Kohn, A. (1996). Five reasons to stop saying "good job!” In B. A. Marlowe \& A.S.

Canestrari. (Eds.). Educational Psychology in Context: Readings for Future Teachers (pp.200-205). Thousand Oaks: Sage.

Knoblauch, C., \& Brannon, L. (1981). Teacher commentary on student writing: The state of the art. Freshman English News, 10(2), 1-4. 
Maclellan, F. (2005). Academic achievement: The role of praise in motivating students. Active Learning in Higher Education, 6(3), 194-206. https://doi.org/10.1177/1469787405057750

Nelson, J. A. P., Young, B. J., Young, E. L., \& Cox, G. (2010). Using teacher-written praise notes to promote a positive environment in a middle school. Preventing School Failure, 54(2), 119-125. https://doi.org/10.1080/10459880903217895

Parodi, L. M. (2008). Filsofia: Fundamentos de la Educatcion, Vision, Historica, Sistematica y Educativia de la Filosofia Occidental. Hato Rey: Publicaciones Puertorriquenas.

Partin, T. C. M., Robertson, R. E., Maggin, D. M., Oliver, R. M., \& Wehby, J. H. (2009). Using teacher praise and opportunities to respond to promote appropriate student behavior. Preventing School Failure: Alternative Education for Children and Youth, 54(3), 172-178. https://doi.org/10.1080/10459880903493179

Razali, R., \& Jupri, R. (2014). Exploring Teacher Written Feedback and Student Revisions on ESL Students' Writing. IOSR Journal of Humanities and Social Science, 19(5), 63-70. https://doi.org/10.9790/0837-19556370

Skipper, Y., \& Douglas, K. (2012, June). Is no praise good praise? Effects of positive feedback on children's and university students' responses to subsequent failures. British Journal of Educational Psychology, 82(2), 327-339. https://doi.org/10.1111/j.2044-8279.2011.02028.x

Toshalis, E., \& Nakkula, M. J. (2012). Motivation, engagement, and student voice. In The Students at The Center Series. studentsatthecenterhub.org.

Walker, M. (2009). An investigation into written comments on assignments: Do students find them usable? Assessment \& Evaluation in Higher Education, 34(1), 67-78. https://doi.org/10.1080/02602930801895752

Wheatley, R. K., West, R. P., Charlton, C. T., Sanders, R. B., Smith, T. G., \& Taylor, M. J. (2009). Improving behavior through differential reinforcement: A praise note system for elementary school students. Education and Treatment of Children, 32(4), 551-571. http://www.facultyfocus.com/articles/educational-assessment/praise-undermining-student-motivation/\#sthash.js 7MqxqP.dpuf. https://doi.org/10.1353/etc.0.0071 